\title{
Bufalin induced apoptosis of bladder carcinoma cells through the inactivation of $\mathrm{Na}+\mathrm{K}+$-ATPase
}

\author{
HOUBAO HUANG ${ }^{1,2}$ and WEI ZHANG ${ }^{1}$ \\ ${ }^{1}$ Department of Urology, The First Affiliated Hospital With Nanjing Medical University, Nanjing, Jiangsu 210029; \\ ${ }^{2}$ Department of Urology, The First Affiliated Hospital of Wannan Medical College, Wuhu, Anhui 241001, P.R. China
}

Received February 9, 2018; Accepted June 20, 2018

DOI: $10.3892 / \mathrm{ol} .2018 .9142$

\begin{abstract}
Bufalin has been demonstrated to possess a wide range of pharmacological effects. Among these is its antitumour effect, which has been confirmed in multiple organs or tissues and provoked many concerns. However, its cytostatic effect and underlying mechanism in bladder cancer has not thoroughly been elucidated. This study aimed to investigate the hypothesis that Bufalin induces cell apoptosis and inhibits cell growth in bladder cancer through the inactivation of $\mathrm{Na}+/ \mathrm{K}+-\mathrm{ATPase}$ (NKA). In the current study, it was demonstrated that Bufalin remarkably inhibited cell viability and induced cell apoptosis in bladder cancer cell line T24. Subsequently, we found that the expression of NKA was significantly supressed in Bufalin-treated cells and the NKA- $\alpha 3$ isoform was most sensitive to Bufalin among all $\alpha$ subunits of NKA. By transfection with NKA- $\alpha 3$ overexpressing plasmids, the expression of the NKA- $\alpha 3$ subunit was upregulated and NKA- $\alpha 3$ overexpression was found to markedly attenuated Bufalin-induced cell apoptosis in T24 cells, suggesting NKA- $\alpha 3$ played a critical role in Bufalin-induced cell apoptosis. Taken together, the present study confirmed that Bufalin promotes tumour apoptosis and inhibits tumour growth in bladder cancer in vitro, and this antitumour effect may be ascribed to the inactivation of NKA.
\end{abstract}

\section{Introduction}

Bladder cancer is a common malignancy and a primary cause of cancer-related morbidity and mortality in the urinary system worldwide (1). In recent years, the incidence of bladder cancer continues to rapidly increase, with approximately $75-85 \%$ of the diagnosed tumours non-muscle-invasive bladder cancer (2). With the development of detection and diagnostic techniques,

Correspondence to: Professor Wei Zhang, Department of Urology, The First Affiliated Hospital With Nanjing Medical University, 300 Guangzhou Road, Nanjing, Jiangsu 210029, P.R. China

E-mail: sqsforever@foxmail.com

Key words: bufalin, bladder cancer, ATPase, proliferation, apoptosis, tumour most patients can be detected in the early stage and treated by the transurethral resection of tumours combined with standard intravesical chemotherapy or immunotherapy $(3,4)$. However, 50-70\% of non-muscle-invasive tumours are susceptible to recur and $10-20 \%$ of cases may rapidly progress to muscle-invasive type $(5,6)$. Muscle-invasive bladder cancer is usually accompanied with pelvic lymph node or distant metastasis, leading to poor therapeutic effect and prognosis $(7,8)$. Thus, intravesical chemotherapy or immunotherapy combined with surgery is thus far the most effective treatment strategy for the prevention of tumour recurrence and progress (9). Although these adjuvant drugs have exhibited relatively acceptable effects, they are always associated with multi-drug resistance and strong systemic toxicity. Therefore, exploring more effective drugs with lower toxicity will be helpful in preventing and treating the disease.

Bufalin is a major digoxin-like molecular with immunoreactivity derived from Chan $\mathrm{Su}$, a traditional Chinese medicine extracted from the skin and parotid venom glands of the toad (10). It can also induce a wide range of pharmacological effects, including cardiotonic, anaesthetic, antitumour, antimicrobial, respiration-improving and so on $(11,12)$. In particular, Bufalin has significant antitumour activity in a wide spectrum of tumour models, such as the inhibition of cell proliferation and angiogenesis, induction of cell differentiation and apoptosis, disruption of the cell cycle, reversal of multidrug resistance and modulation of the immune response $(13,14)$. Numerous studies have indicated that NKA is a main target of Bufalin, and an aberrantly expressed NKA subunit is tightly associated with cell apoptosis and proliferation in several cancers $(15,16)$. However, the effect of Bufalin on cell proliferation and apoptosis of bladder cancer cells has not been thoroughly clarified, and the underlying mediating mechanisms such as antitumour effects remain to be elucidated.

The present study aimed to investigate the antitumour effect of Bufalin on bladder cancer and to determine the possible molecular mechanisms of bufalin mediated by $\mathrm{Na}^{+}-\mathrm{K}^{+}$-ATPase (NKA), focusing on cell apoptosis and proliferation.

\section{Materials and methods}

Cell lines and cell culture. Two bladder cancer cell lines, T24 and 5637, were purchased from the American Type Culture Collection (ATCC, Manassas, VA, USA). Cells were cultured 
in RPMI 1640 medium supplemented with $10 \%$ foetal bovine serum (Gibco; Thermo Fisher Scientific, Inc., Waltham, MA, USA) at $37^{\circ} \mathrm{C}$ with $5 \% \mathrm{CO}_{2}$.

Plasmid construction and cell transfection. Human bladder cancer cell line T24 was used to generate cells that express the NKA- $\alpha 3$ subunit. For construction of the vectors, the green fluorescent protein (GFP) coding sequence was inserted in the pIRES-puro vector using EcoRI and NotI digestion enzymes. The coding sequences of the $\alpha 3$ subunit of NKA were ligated into pIRES-puro in frame with GFP. Cell transfection was performed using Lipofectamine 2000 (Invitrogen; Thermo Fisher Scientific, Inc.), according to the manufacturer's protocol. Positive GFP-fluorescent clones were observed under a fluorescence microscope to examine GFP expression. After culture for $48 \mathrm{~h}$, cells were harvested, and total RNA was extracted. Conventional RT-PCR and quantitative real-time PCR (qRT-PCR) were used to detect $\alpha 3$ subunit expression.

Cell proliferation assay. Cell proliferation was measured using a Cell Counting kit-8 (Beyotime Institute of Biotechnology, Jiangsu, China). After being inoculated into 96 -well plates at a density of $2 \times 10^{3}$ cells/well, cells were stained with $20 \mu \mathrm{l}$ of CCK8 reagent $48 \mathrm{~h}$ after transfection. Two h after incubation, cell viability was measured by detecting the absorbance of samples at $450 \mathrm{~nm}$.

Cell apoptosis assay. Cell apoptosis was measured by Annexin V-fluorescein isothiocyanate (FITC)/propidium iodide (PI) staining (BD PharMingen, San Jose, CA, USA) following the manufacturer's instructions. In brief, T24 cells were collected in 6-well plates at a concentration of 105 cells/ml. Then, Annexin V-FITC (5 $\mu \mathrm{l})$ and PI (5 $\mu \mathrm{l})$ were distributed to each well, and the cells were incubated in the dark for 15 min to undergo flow cytometry (BD LSR II; BD PharMingen).

Quantitative real-time PCR. Total RNA was extracted from cancer cells by using TRIzol Reagent (Invitrogen; Thermo Fisher Scientific, Inc.) according to the manufacturer's instructions. After that, all RNAs were reversed transcribed into cDNA using a reverse transcription reagent kit (Takara Biotechnology, Dalian, China). Real-time quantitative PCR was performed via an Applied Biosystems SYBR-Green mix kit and the ABI 7900 Real-Time PCR system (Applied Biosystems Life Technologies, Foster City, CA, USA). Primer sequences are shown in Table I. Relative mRNA expression was normalized to GAPDH. The relative amount of mRNA was calculated using the $2^{-\Delta \Delta C q}$ method (17). All primers are shown in Table I.

Western blot analysis. Cells were collected and lysed using RIPA buffer with PMSF (Beyotime Institute of Biotechnology) on ice. Protein concentration was qualified using a bicinchoninic acid assay (BCA) kit (Beyotime Institute of Biotechnology). Equivalent amounts of protein samples were separated by $10 \%$ sodium dodecyl sulfate-polyacrylamide gel electrophoresis (SDS-PAGE) gel electrophoresis and subsequently transferred to polyvinylidene fluoride (PVDF) membranes. Membranes were blocked in Tris-buffered saline (TBS) containing 5\% non-fat milk. After that, membranes were incubated with primary antibody against subunit $\alpha 1$ (cat. no. ab7671), $\alpha 3$ (cat. no. ab2826; both Abcam, Cambridge, UK) and GAPDH (cat. no. 2118S; Cell Signaling Technology, Inc., Danvers, MA, USA) at $4^{\circ} \mathrm{C}$ overnight, followed by incubation with secondary antibodies, detected by enhanced chemiluminescent (ECL) and qualified using ImageJ software (National Institutes of Health, Bethesda, MD, USA).

Statistical analysis. All data are presented as the mean \pm SD. Differences were assessed by a two-tailed Student's t-test and one-way analysis of variance (ANOVA), and the Student-Newman-Keuls test was used as a post hoc test after ANOVA. $\mathrm{P}<0.05$ was considered to indicate a statistically significant difference. All experiments were performed at least 3 times. Statistical analyses were carried out using SPSS 19.0 (SPSS, Inc., Chicago, IL, USA).

\section{Results}

Bufalin inhibits cell viability and induces cell apoptosis in bladder cancer cell lines. To investigate the pharmacological effect of Bufalin on bladder cancer, two bladder cancer cell lines (T24, 5637) were employed to simulate different stages of the tumour (Fig. 1). A CCK-8 assay was performed to examine sensitivities to Bufalin in tumour cells. As the result showed, compared with 5,637 cells, cell viability of T24 was significantly inhibited by Bufalin at a concentration of $100 \mathrm{nM}$ (Fig. 1A). A cell apoptosis assay was performed to determine the cytostatic effect of Bufalin. As the result showed, compared with the control group, Bufalin induced remarkable apoptosis in a total of three cell lines, and the apoptosis rate in T24 cells was the most significant (Fig. 1C). Therefore, T24 cells and $100 \mathrm{nM}$ concentration of Bufalin were used for subsequent research. Western blotting was additionally performed to explore the protein expression of apoptotic phenotypes caspase- 3 and $\mathrm{Bcl}-2$. In accordance with our expectation, the expression of caspase- 3 was markedly upregulated in contrast with the expression of Bcl-2 (Fig. 1B). These results demonstrated that Bufalin inhibits tumour cell growth and promotes cell apoptosis in bladder cancer.

Bufalin-induced apoptosis in bladder cancer cells through inactivation of NKA. To determine whether ATPase is involved in Bufalin-induced cell apoptosis, we examined the expression of three subunits of ATPase $(\alpha 1, \alpha 2$ and $\alpha 3)$ on protein or mRNA level in T24 cells. The results revealed that the expression of $\alpha 3$-ATPase was significantly inhibited by Bufalin on both the protein and mRNA level, while the expression of $\alpha 1$-ATPase and $\alpha 2$-ATPase was moderately changed (Fig. 2). These findings suggest that NKA is involved in the cell growth and apoptosis of bladder cancer, and the $\alpha 3$ subunit of ATPase may play an important role among the three subunits.

a3-NKA overexpression attenuated Bufalin-induced apoptosis in bladder cancer cells. To further investigate the role of $\alpha 3$ subunit of NKA in Bufalin-induced cytostatic effect in bladder cancer cells, we constructed plasmids encoding $\alpha 3$ isoforms of ATPase to overexpress $\alpha 3$-ATPase. The transfection efficiency was examined by western blot analysis. As the 
Table I. Primer sequences used in quantitative polymerase chain reaction.

\begin{tabular}{lll}
\hline Name & Primer & \multicolumn{1}{c}{ Sequence 5' to 3' } \\
\hline Na+/K+-ATPase a1 & Forward & AGTACACGGCAGTGATCTAAAGG \\
& Reverse & CAGTCACAGCCACGATAGCAC \\
$\mathrm{Na}+$ K+-ATPase a2 & Forward & GGAGATGCAAGATGCCTTCA \\
& Reverse & GCTCATCCGTGTCGAATTGA \\
$\mathrm{Na}+\mathrm{K}+$-ATPase a3 & Forward & GACCTCATTTGACAAGAGTTCGC \\
& Reverse & GGGCAGACTCAGACGCATC \\
Bcl-2 & Forward & TTTGATTCTCCTGGCTGTCT \\
& Reverse & CTGATTTGACCATTTGCCTG \\
Caspase-3 & Forward & GACAACAACGAAACCTCCG \\
GAPDH & Reverse & AGGGTTAGCTGCATCGACA \\
& Forward & ACAGCAACAGGGTGGTGGAC \\
& Reverse & TTTGAGGGTGCAGCGAACTT \\
\hline
\end{tabular}

western blot result showed, compared with the control group, the expression of $\alpha 3$-ATPase was remarkably upregulated on the protein level (Fig. 3A). Subsequently, we explored the expression of $\alpha 3$-ATPase, caspase-3 and Bcl-2 under Bufalin treatment by western blotting. As the data showed, compared with the Bufalin group, the expression of $\alpha 3$-ATPase was moderately increased in the $\alpha 3$-isoform overexpression group, while the expression change of caspase- 3 and Bcl-2 induced by Bufalin was significantly weakened in $\alpha 3$-isoform overexpressing cells (Fig. 3B). The results from the cell apoptosis assay showed that compared with the Bufalin group, overexpression of $\alpha 3$-ATPase attenuated Bufalin-induced cell apoptosis (Fig. 3C). Taken together, these results confirmed that $\alpha 3$ subunit of NKA was the most important subunit in cell growth and apoptosis of bladder cancer.

\section{Discussion}

Bladder cancer is one of the most common urological malignant tumours worldwide and is the 6th leading cause of new cancer cases and the 9th leading cause of cancer-associated mortality among all types of cancer $(18,19)$. The majority of non-muscle-invasive bladder cancers can be diagnosed and treated early for their clinical symptoms and signs; however, non-muscle-invasive bladder cancer is vulnerable to recur or progress to invasive-muscle disease, which is considered an aggressive and extremely virulent disease (20). Therefore, it is necessary to search for more effective chemotherapy drugs to improve the prognosis and survival of patients. Bufalin is a topoisomerase II inhibitor and is involved in the regulation of the development process of leukaemia, gastric, colon, breast, and ovarian cancer and other malignant tumours $(21,22)$. Based on these results, we aimed to demonstrate that Bufalin may play an antitumour role in bladder cancer cells by downregulation of NKA.

Apoptosis is a self-killing process of programmed cell death that includes a range of cellular, morphological and biochemical changes (23). It is known that human mammalian cells exhibit two major pathways of apoptosis: The intrinsic (or mitochondrial) and extrinsic (or death receptor) signal transduction pathways (24). It has been demonstrated that the mitochondrial pathway process of apoptosis is regulated by gene expression and its activation may stimulate the degradation of cellular substrates and participate in the pathogenesis of many diseases (25). Bcl-2 may prevent the release of cytochrome $c$ from the mitochondria to inhibit apoptosis, and caspase- 3 is considered the convergence point of multiple apoptosis-activating signals that determines the extent of apoptosis. Its activation means an irreversible commitment to cellular apoptosis (26). In previous study, Qi et al (27) showed that Bufalin can reduce the expression level of Bcl-2 and stimulate the activation of caspase- 3 to promote cell apoptosis through mitochondria-mediated pathways in hepatocellular carcinoma cells. One of the major features of Bufalin in the present study is the inhibition of proliferation, a vital process that plays an important role in maintaining normal tissue structure and functions (28). Recent studies showed that Bufalin induced cell apoptosis in non-small cell lung cancer, choriocarcinoma and osteosarcoma cells (29-31). To explore the effect of Bufalin on cell apoptosis and proliferation in bladder cancer, we performed an MTT assay, cell apoptosis assay and western blot. The results showed that the T24 cell line was markedly inhibited and the most sensitive to Bufalin. Moreover, Bufalin treatment resulted in the cleavage of caspase-3 activation while blocking Bcl-2 expression. These results indicated that Bufalin promotes apoptosis and inhibits proliferation in bladder cancer.

NKA is a trans-membrane protein complex in mammals, which pumps three $\mathrm{Na}^{+}$ions out and two $\mathrm{K}+$ ions into a cell per molecule of hydrolysed ATP to regulate the intracellular ion gradients (32). Apart from its function as an ion pump, NKA is also a multifunctional protein in signal transduction, cell junctions, adhesion and motility $(33,34)$. NKA contains four isoforms of the $\alpha$-subunit $(\alpha 1, \alpha 2, \alpha 3$ and $\alpha 4)$ and three of the $\beta$-subunit $(\beta 1, \beta 2$ and $\beta 3)$ in vertebrates, and the $\alpha$-subunit of NKA is the active subunit participated in the binding of cardiac steroids and NKA $(16,35)$. Generally, the 


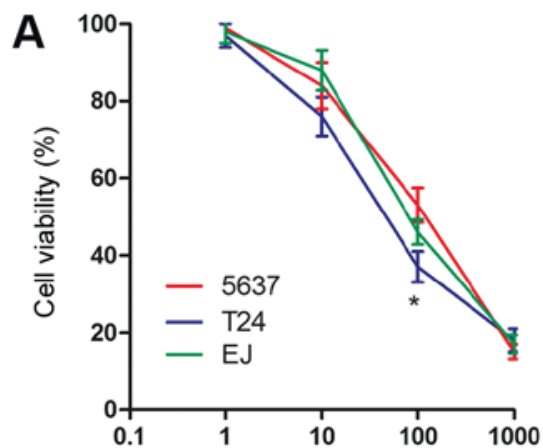

C
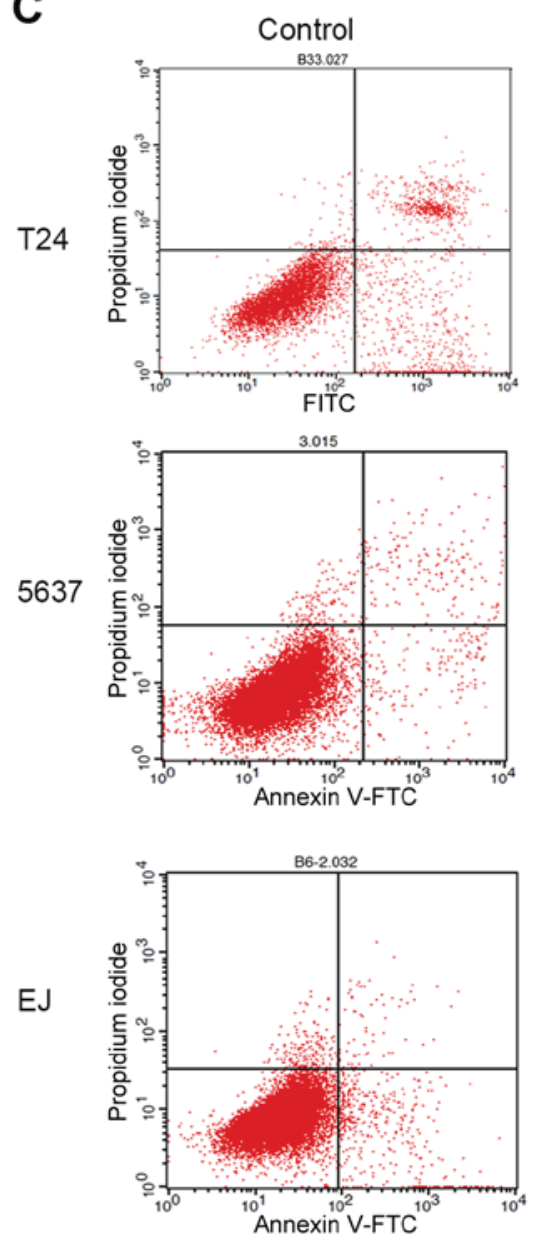

B
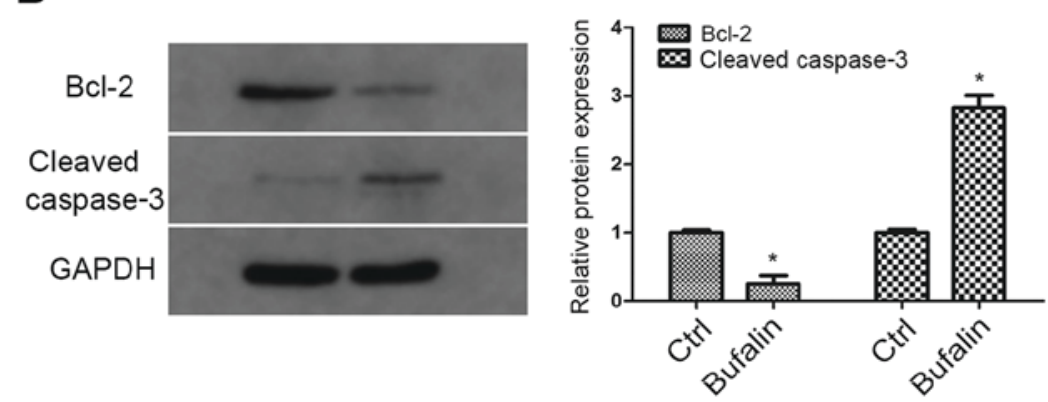

Bufalin
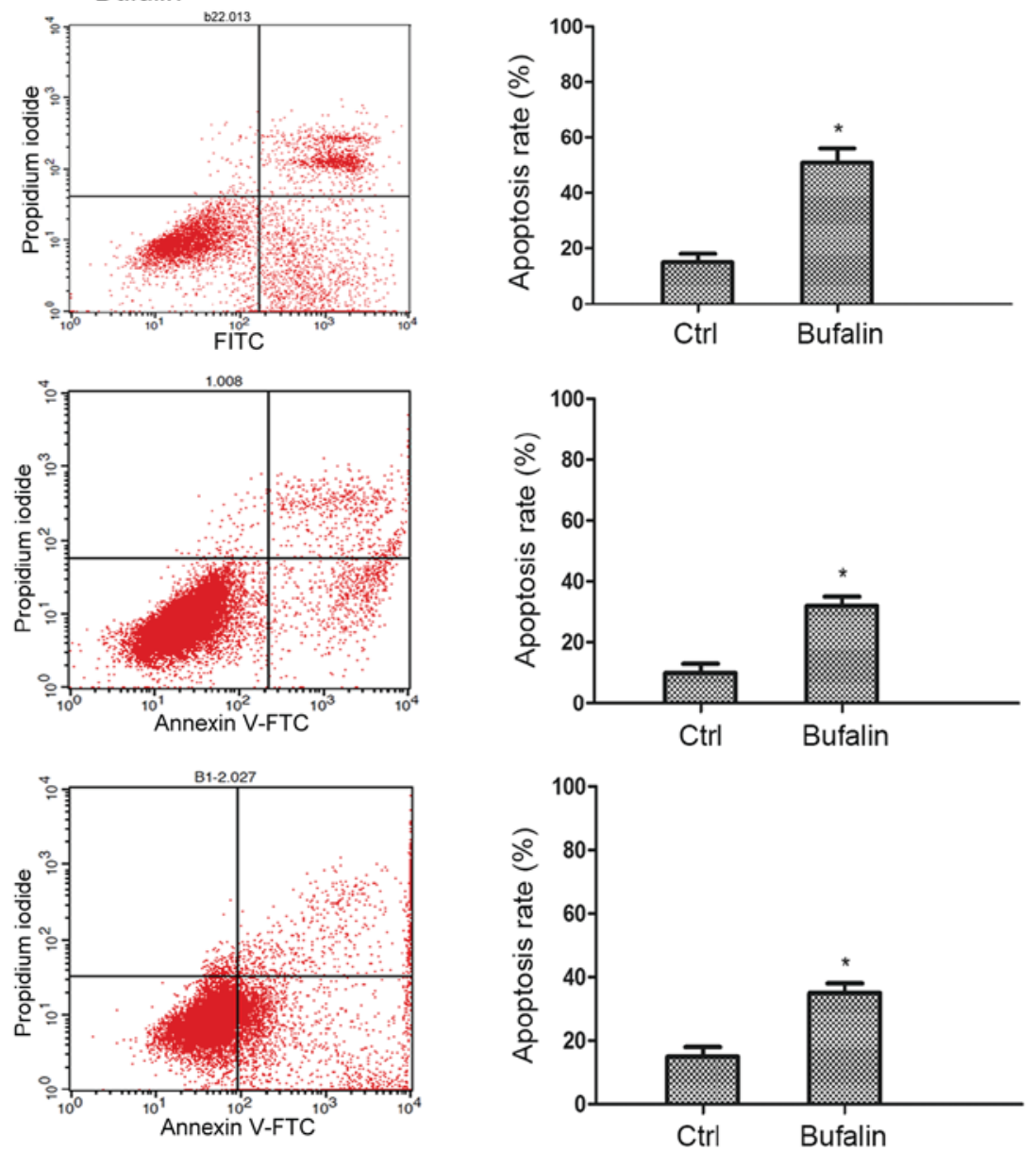

Figure 1. Bufalin inhibits cell viability and induces cell apoptosis in bladder cancer cell lines. (A) Three types of bladder cancer cell lines were exposed to various concentrations of bufalin $(1$ to $1,000 \mathrm{nM}$ ) for $24 \mathrm{~h}$. Cell proliferation was determined with Cell Counting kit- 8 assay. (B) Western blotting was performed to examine the expression of Bcl-2 and cleaved caspase-3. (C) Annexin V-FITC/PI assay was performed to analyze cell apoptosis in T24 cells treated with Bufalin. Data are presented as means \pm SD of three separated experiments ( $\mathrm{P}<0.05$ vs. control group). FITC, fluorescein isothiocyanate; PI, propidium iodide.
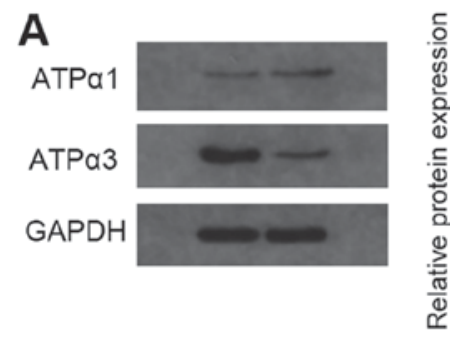
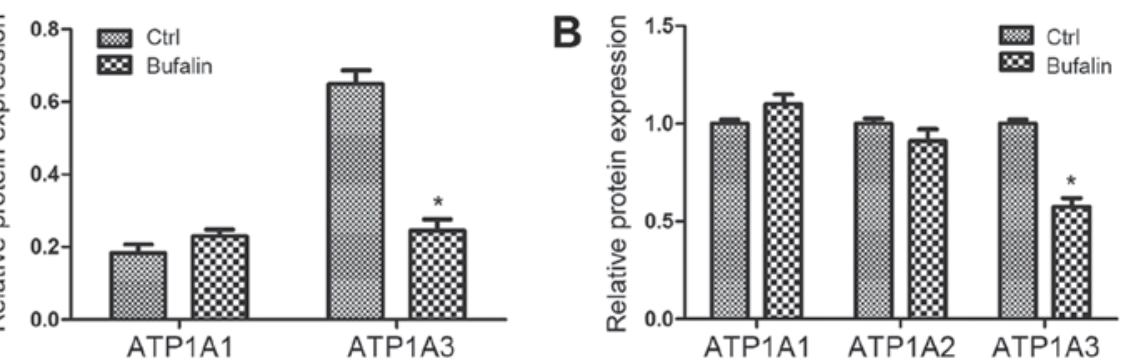

Figure 2. Bufalin-induced apoptosis in bladder cancer cells through inactivation of $\mathrm{Na}^{+}-\mathrm{K}^{+}$-ATPase. (A) The protein expression of Na+/K+-ATPase $\alpha 1$ and $\alpha 3$ was detected by western blot analysis. GAPDH was used as a loading control. (B) The mRNA level of $\mathrm{Na}^{+}-\mathrm{K}^{+}$-ATPase $\alpha 1 \alpha 2$ and $\alpha 3$ was detected by qRT-PCR with specific primers of $\alpha 1 \alpha 2$ and $\alpha 3$ isoforms. GAPDH was used as a loading control. Data are presented as means \pm SD of three independent experiments ("P<0.05 vs. control group). qRT-PCR, quantitative real-time PCR. 

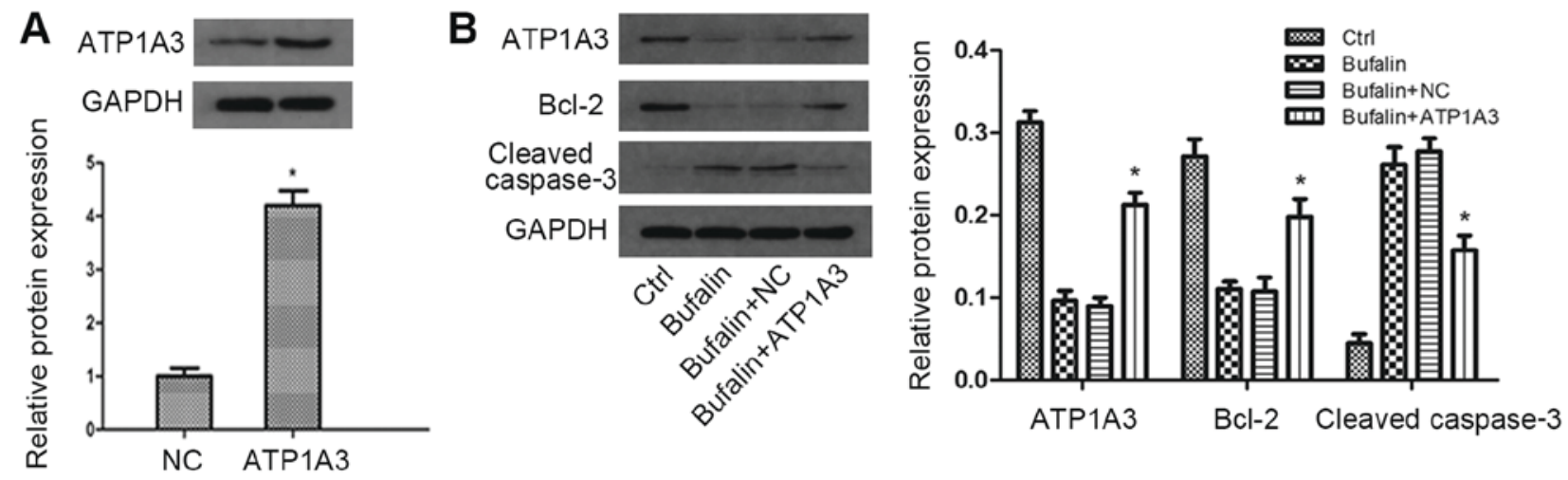

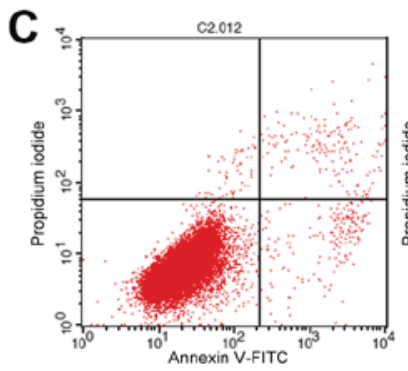

Ctrl

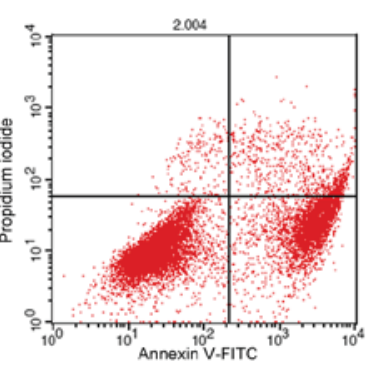

Bufalin

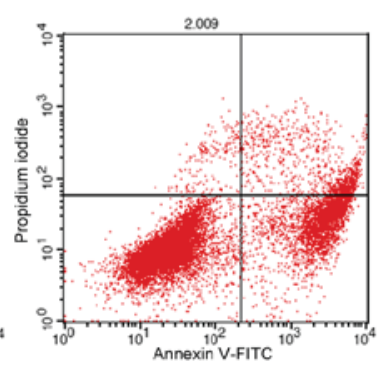

Bufalin+NC

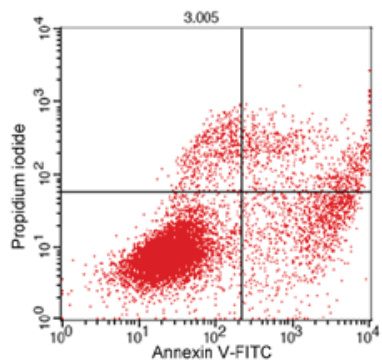

Bufalin+ATP1A3

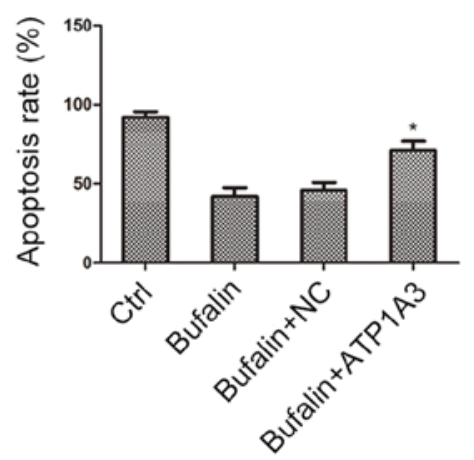

Figure 3. $\alpha 3-\mathrm{Na}+\mathrm{-K}+$-ATPase overexpression attenuated Bufalin-induced apoptosis in bladder cancer cells. (A) T24 cells were transfected with vectors containing sequences of $\alpha 3$ subunit of ATPase. Transfection efficiency was determined using western blot. (B) T24 cells overexpressing $\alpha 3$ isoform of ATPase were treated with Bufalin for $2 \mathrm{~h}$. The protein levels of $\alpha 3$ isoform, Bcl-2 and cleaved caspase- 3 were detected using western blot. GAPDH was used as a loading control. (C) Annexin V-FITC/PI assay was performed to examine cell apoptosis in transfected T24 cells treated with Bufalin. Data are presented as the mean $\pm \mathrm{SD}$ of three independent experiments ("P<0.05 vs. NC group or Bufalin $+\mathrm{NC}$ group). FITC, fluorescein isothiocyanate; PI, propidium iodide.

$\alpha 1$ subunit is widely expressed in various cell types, and the $\alpha 2$ subunit is mostly expressed in the heart muscle, skeletal muscle and brain. The $\alpha 3$ subunit is found in the central nervous system, ovaries and placental tissues, and the $\alpha 4$ subunit is restricted to the testes and is synthesized at the stage of spermatogonium $(36,37)$. A number of in vivo and in vitro studies have confirmed that the $\alpha 1$ and $\alpha 3$ subunit is aberrantly expressed in a wide range of tumours. For example, the expression level of NKA- $\alpha 1$ is upregulated in glioblastoma, lung and skin cancers, while is downregulated in bowel cancer. On the other hand, NKA- $\alpha 3$ is found to be upregulated in rectal and colorectal cancers $(38,39)$. Our results also showed that the expression level of the $\alpha 3$ subunit in bladder cancer cells was significantly upregulated among all $\alpha$ subunits. Furthermore, previous studies have demonstrated that NKA is a main target of Bufalin and is tightly associated with cell apoptosis and proliferation in malignant tumour occurrence and progression. For example, Bufalin induces apoptosis by downregulating NKA in human lymphoblastic leukaemia cells (40), and Bufalin suppresses hepatocellular carcinoma cells proliferation by negatively regulating NKA (41). In our study, we found that Bufalin significantly inhibited $\alpha 3$ subunit expression in T24 cells. By transfection with $\alpha 3$ isoform overexpressing plasmids, we found that compared with Bufalin groups, cell apoptosis was markedly attenuated in NKA- $\alpha 3$ overexpressing cells. These results suggested that the $\alpha 3$ isoform of NKA played a critical role in Bufalin-induced cell apoptosis.

In conclusion, our study indicated that Bufalin can promote cell apoptosis in bladder cancer, and this cytostatic effect may be ascribed to the inactivation of NKA. These findings implied that Bufalin has the potential to be applied as an effective antitumour medicine in the treatment of bladder cancer.

\section{Acknowledgements}

Not applicable. 


\section{Funding}

No funding was received.

\section{Availability of data and materials}

The datasets during and/or analysed during the current study available from the corresponding author on reasonable request.

\section{Authors' contributions}

HH was involved in the conception and design of the study, and manuscript writing. ZW was involved in the study design, supervision of all phases of the study, data collection and data analysis.

\section{Ethics approval and consent to participate}

Not applicable.

\section{Patient consent for publication}

Not applicable.

\section{Competing interests}

The authors declare that they have no competing interests.

\section{References}

1. Antoni S, Ferlay J, Soerjomataram I, Znaor A, Jemal A and Bray F: Bladder cancer incidence and mortality: A global overview and recent trends. Eur Urol 71: 96-108, 2017.

2. Wirth M, Plattner VE and Gabor F: Strategies to improve drug delivery in bladder cancer therapy. Expert Opin Drug Deliv 6: 727-744, 2009

3. Liu H, Chang JK, Hou JQ, Zhao ZH and Zhang LD: Inhibition of miR-221 influences bladder cancer cell proliferation and apoptosis. Eur Rev Med Pharmacol Sci 21: 3193-3199, 2017.

4. Akagashi K, Tanda H, Kato S, Ohnishi S, Nakajima H, Nanbu A, Nitta T, Koroku M, Sato Y and Hanzawa T: Recurrence pattern for superficial bladder cancer. Int J Urol 13: 686-691, 2006.

5. Herr HW: High-risk superficial bladder cancer: Transurethral resection alone in selected patients with T1 tumor. Semin Urol Oncol 15: 142-146, 1997.

6. Pasin E, Josephson DY, Mitra AP, Cote RJ and Stein JP: Superficial bladder cancer: An update on etiology, molecular development, classification, and natural history. Rev Urol 10 31-43, 2008.

7. Masson-Lecomte A, Rava M, Real FX, Hartmann A, Allory $\mathrm{Y}$ and Malats $\mathrm{N}$ : Inflammatory biomarkers and bladder cancer prognosis: A systematic review. Eur Urol 66: 1078-1091, 2014.

8. Rose TL, Deal AM, Nielsen ME, Smith AB and Milowsky MI: Sex disparities in use of chemotherapy and survival in patients with advanced bladder cancer. Cancer 122: 2012-2020, 2016.

9. Yoshida T, Okuyama H, Nakayama M, Endo H, Nonomura N, Nishimura K and Inoue M: High-dose chemotherapeutics of intravesical chemotherapy rapidly induce mitochondrial dysfunction in bladder cancer-derived spheroids. Cancer Sci 106: 69-77, 2015.

10. Wang J, Chen C, Wang S, Zhang Y, Yin P, Gao Z, Xu J, Feng D, Zuo Q, Zhao R and Chen T: Bufalin inhibits HCT116 colon cancer cells and its orthotopic xenograft tumor in mice model through genes related to apoptotic and PTEN/AKT pathways. Gastroenterol Res Pract 2015: 457193, 2015.

11. Yin PH, Liu X, Qiu YY, Cai JF, Qin JM, Zhu HR and Li Q Anti-tumor activity and apoptosis-regulation mechanisms of bufalin in various cancers: New hope for cancer patients. Asian Pac J Cancer Prev 13: 5339-5343, 2012.
12. Yang LH, Zhang HZ, Zhang B, Chen F, Lai ZH, Xu LF and Jin XQ: Studies on the chemical constituents from the skin of Bufo bufo gargarizans Cantor. Yao Xue Xue Bao 27: 679-683, 1992 (In Chinese).

13. Yin P, Wang Y, Qiu Y, Hou L, Liu X, Qin J, Duan Y, Liu P, Qiu M and Li Q: Bufalin-loaded mPEG-PLGA-PLL-cRGD nanoparticles: Preparation, cellular uptake, tissue distribution, and anticancer activity. Int J Nanomedicine 7: 3961-3969, 2012.

14. Han KQ, Huang G, Gu W, Su YH, Huang XQ and Ling CQ: Anti-tumor activities and apoptosis-regulated mechanisms of bufalin on the orthotopic transplantation tumor model of human hepatocellular carcinoma in nude mice. World J Gastroenterol 13: 3374-3379, 2007.

15. Koh CH, Wu J, Chung YY, Liu Z, Zhang RR, Chong K, Korzh V, Ting S, Oh S, Shim W, et al: Electronic supplementary material identification of a $\mathrm{Na}+\mathrm{K}+-\mathrm{ATPase}$ inhibition-independent proarrhythmic ionic mechanisms of cardiac glycosides. Sci Rep 7: 2465, 2017.

16. Liu M, Feng LX, Sun P, Liu W, Wu WY, Jiang BH, Yang M, Hu LH, Guo DA and Liu X: A novel bufalin derivative exhibited stronger apoptosis-inducing effect than bufalin in A549 lung cancer cells and lower acute toxicity in mice. PLoS One 11: e0159789, 2016.

17. Rao $X$, Huang $X$, Zhou $Z$ and Lin $X$ : An improvement of the $2^{\wedge}$ (-delta delta CT) method for quantitative real-time polymerase chain reaction data analysis. Biostat Bioinforma Biomath 3: 71-85, 2013

18. Fan B, Zhang X, Ma Y and Zhang A: Fangchinoline induces apoptosis, autophagy and energetic impairment in bladder cancer. Cell Physiol Biochem 43: 1003-1011, 2017.

19. Xu H, Xie L, Liu X, Zhang Y, Shen Z, Chen T, Qiu X, Sha N, Xing $\mathrm{C}, \mathrm{Wu} \mathrm{Z}$, et al: Impact of squamous and/or glandular differentiation on recurrence and progression following transurethral resection for non-muscle invasive urothelial carcinoma of bladder. Oncol Lett 14: 3522-3528, 2017.

20. Tran K and Severn M: Blue light cystoscopy in patients with suspected non-muscle invasive bladder carcinoma: A review of clinical utility [Internet]. Ottawa (ON): Canadian Agency for Drugs and Technologies in Health, 2017.

21. Kang KH, Han MH, Jeong JW, Park C, Lee SH, Lee HW, Hong SH, Choi $\mathrm{YH}$ and Hong SH: Bufalin sensitizes human bladder carcinoma cells to TRAIL-mediated apoptosis. Oncol Lett 14: 853-859, 2017.

22. Zhang N, Xie Y, Tai Y, Gao Y, Guo W, Yu W, Li J, Feng X, Hao J, Gao Y, et al: Bufalin inhibits hTERT expression and colorectal cancer cell growth by targeting CPSF4. Cell Physiol Biochem 40: 1559-1569, 2016.

23. Vaux DL and Korsmeyer SJ: Cell death in development. Cell 96: 245-254, 1999

24. Kerr JF, Wyllie AH and Currie AR: Apoptosis: A basic biological phenomenon with wide-ranging implications in tissue kinetics. Br J Cancer 26: 239-257, 1972.

25. Arnoult D, Parone P, Martinou JC, Antonsson B, Estaquier J and Ameisen JC: Mitochondrial release of apoptosis-inducing factor occurs downstream of cytochrome c release in response to several proapoptotic stimuli. J Cell Biol 159: 923-929, 2002.

26. Liang H, Yu F, Tong Z, Yuan B and Wang C: Effect of ischemia post-conditioning on skeletal muscle oxidative injury, mTOR, Bax, Bcl-2 proteins expression, and HIF- $1 \alpha / \beta$-actin mRNA, IL-6/ $/$-actin mRNA and caveolin-3/ $\beta$-actin mRNA expression in ischemia-reperfusion rabbits. Mol Biol Rep 40: 507-514, 2013.

27. Qi F, Inagaki Y, Gao B, Cui X, Xu H, Kokudo N, Li A and Tang W: Bufalin and cinobufagin induce apoptosis of human hepatocellular carcinoma cells via Fas- and mitochondria-mediated pathways. Cancer Sci 102: 951-958, 2011.

28. Hanahan D and Weinberg RA: Hallmarks of cancer: The next generation. Cell 144: 646-674, 2011

29. Jiang Y, Zhang Y, Luan J, Duan H, Zhang F, Yagasaki K and Zhang G: Effects of bufalin on the proliferation of human lung cancer cells and its molecular mechanisms of action. Cytotechnology 62: 573-583, 2010.

30. Takai N, Ueda T, Ishii T, Kira N, Nishida M, Nishida Y, Nasu $\mathrm{K}$ and Narahara H: Effects of bufalin on the proliferation of human choriocarcinoma cells. Int J Gynecol Cancer 21: 1105-1109, 2011.

31. Zhang J, Sha J, Zhou Y, Han K, Wang Y, Su Y, Yin X, Hu H and Yao Y: Bufalin inhibits proliferation and induces apoptosis in osteosarcoma cells by downregulating MicroRNA-221. Evid Based Complement Alternat Med 2016: 7319464, 2016. 
32. Ren YP, Zhang MJ, Zhang T and Huang RW: Dual effects of ouabain on the regulation of proliferation and apoptosis in human umbilical vein endothelial cells: Involvement of $\mathrm{Na}(+)-\mathrm{K}(+)$-ATPase $\alpha$-subunits and NF- $\mathrm{BB}$. Int J Clin Exp Med 7: 1214-1222, 2014

33. Kaplan JH: Biochemistry of Na,K-ATPase. Annu Rev Biochem 71: 511-535, 2002.

34. Mobasheri A, Avila J, Cózar-Castellano I, Brownleader MD, Trevan M, Francis MJ, Lamb JF and Martín-Vasallo P: Na+, K+-ATPase isozyme diversity; comparative biochemistry and physiological implications of novel functional interactions. Biosci Rep 20: 51-91, 2000.

35. Nguyen AN, Jansson K, Sánchez G, Sharma M, Reif GA Wallace DP and Blanco G: Ouabain activates the Na-K-ATPase signalosome to induce autosomal dominant polycystic kidney disease cell proliferation. Am J Physiol Renal Physiol 301: F897-F906, 2011.

36. Felippe Gonçalves-de-Albuquerque C, Ribeiro Silva A, Ignácio da Silva C, Caire Castro-Faria-Neto $\mathrm{H}$ and Burth P: Na/K pump and beyond: $\mathrm{Na} / \mathrm{K}-\mathrm{ATP}$ ase as a modulator of apoptosis and autophagy. Molecules 22: pii: E578, 2017.

37. Dostanic-Larson I, Lorenz JN, Van Huysse JW, Neumann JC, Moseley AE and Lingrel JB: Physiological role of the alpha1- and alpha2-isoforms of the Na+-K+-ATPase and biological significance of their cardiac glycoside binding site. Am J Physiol Regul Integr Comp Physiol 290: R524-R528, 2006.
38. Sakai H, Suzuki T, Maeda M, Takahashi Y, Horikawa N, Minamimura T, Tsukada K and Takeguchi N: Up-regulation of $\mathrm{Na}(+), \mathrm{K}(+)$-ATPase alpha 3-isoform and down-regulation of the alpha1-isoform in human colorectal cancer. FEBS Lett 563: 151-154, 2004.

39. Mijatovic T, Ingrassia L, Facchini V and Kiss R: Na+/K+-ATPase alpha subunits as new targets in anticancer therapy. Expert Opin Ther Targets 12: 1403-1417, 2008.

40. Kawazoe N, Aiuchi T, Masuda Y, Nakajo S and Nakaya K: Induction of apoptosis by bufalin in human tumor cells is associated with a change of intracellular concentration of $\mathrm{Na}+$ ions. J Biochem 126: 278-286, 1999.

41. Xu Y, Liu X, Schwarz S, Hu L, Guo D, Gu Q and Schwarz W: Inhibitory efficacy of bufadienolides on $\mathrm{Na}+\mathrm{K}+$-pump activity versus cell proliferation. Biochem Biophys Rep 6: $158-164,2016$

c) (i) (3) This work is licensed under a Creative Commons EY NO ND Attribution-NonCommercial-NoDerivatives 4.0 International (CC BY-NC-ND 4.0) License. 